\title{
Efficiency of Oxygen Therapy by Simple Face Mask and Nasal Cannula for Acute Respiratory Failure in Infants and Young Children
}

\author{
Ioana D. BADIU TIŞA', Sorana D. BOLBOACĂ ${ }^{2 *}$, Nicolae MIU³, Daniela IACOB ${ }^{1}$ \\ ${ }^{1}$ Department Pediatrics, Iuliu Hațieganu University of Medicine and Pharmacy, Cluj-Napoca, Romania \\ ${ }^{2}$ Department of Medical Informatics and Biostatistics, Iuliu Hațieganu University of Medicine and \\ Pharmacy, Cluj-Napoca,Romania; sbolboaca@umfcluj.ro (*correspondingauthor) \\ ${ }^{3}$ Department Pediatrics, Iuliu Hațieganu University of Medicine and Pharmacy, Cluj-Napocam Romania
}

\begin{abstract}
Premises: Acute respiratory failure caused by respiratory diseases, which is a frequent pathology in infants and young children, requires oxygen therapy, which can be administered by different devices. Objectives: To evaluate the efficiency of two devices for oxygen administration by determining a clinical appraisal score for acute respiratory failure in infants and young children by oxygen therapy using simple face masks and nasal cannulas. Material and methods: 74 children, aged between one month and 3 years were included in our study. Oxygen therapy was administered by face mask to 38 patients, and by nasal cannula to 36 patients. A clinical appraisal score of respiratory failure was calculated both before and after oxygen therapy. Oxygen saturation was measured by pulse oximetry $\left(\mathrm{SpO}_{2}\right)$ and arterial or capillary blood gas $\left(\mathrm{SaO}_{2}\right)$ before, and 30 minutes and 60 minutes after the initiation of oxygen therapy. Results: We found an improvement in the clinical score regardless of the method of administration; this improvement was more obvious at 60 minutes than at the 30 min evaluation $(\mathrm{p}<0.001)$. The differences were statistically significant $(\mathrm{p}<0.0001)$ for all the measurements (baseline vs. 30 minutes, baseline vs. 60 minutes, 30 minutes vs. 60 minutes). An increase in both $\mathrm{SaO}_{2}$ and $\mathrm{SpO}_{2}$ values was found ( $\left.\mathrm{p}<0.001\right)$. Conclusions: The clinical score for acute respiratory failure and the $\mathrm{SaO}_{2}$ and $\mathrm{SpO}_{2}$ values significantly improved after oxygen therapy.
\end{abstract}

Keywords: acute respiratory failure, face mask, nasal cannula, oxygen therapy, $\mathrm{SaO}_{2}$ (capillary blood gas parameters on $\mathrm{pH}$ Astrup), $\mathrm{SpO}_{2}$ (oxygen saturation measured in capillary blood by pulse oximeter)

\section{Introduction}

Acute respiratory failure is a syndrome resulting from the incapacity of the respiratory system to provide sufficient oxygen for metabolic needs and / or to eliminate the carbon dioxide produced within the body (Gherasim, 2003; Frankel and DiCarlo, 2003). Adequate tissue oxygenation is achieved physiologically by spontaneous ventilation and adequate circulation. The etiology of acute respiratory failure (ARF) in infants and young children varies; however, acute respiratory infections are predominant, accounting for more than 50\% of the cases (Man and Nanulescu, 2006; Andreica and Miu, 2010). Besides etiologic treatment, patients with respiratory diseases and acute respiratory failure also require oxygen treatment by oxygen therapy, which is essential for maintaining adequate tissue oxygenation (Acalovschi, 2002; Ionescu, 2010; Lee et al., 2013). Oxygen therapy uses numerous methods, which have proved their validity for both adults and older children with spontaneous breathing (AARC, 2002; Stoll and Kliegman, 2003). The techniques of oxygen therapy for infants and young children are still highly controversial, and can be administered by simple face mask, nasal cannula or oxygen hood. The therapeutic response to oxy- gen administration is appraised by monitoring respiratory failure and oxygen saturation $\left(\mathrm{SaO}_{2}\right)$ (Wood, 1975; Butnariu et al., 2005).

The aim of this study was to assess the efficiency of oxygen therapy by two methods: simple face mask and nasal cannula for acute respiratory failure caused by respiratory diseases in infants and young children.

\section{Materials and methods}

A number of 74 patients suffering from acute respiratory failure were studied. The sample was divided into two groups, according to the method of oxygen therapy: oxygen was administered by simple face mask to $38 \mathrm{pa}-$ tients, and by nasal cannula to 36 patients. The study was a prospective cohort study, and was conducted between October 2007 and December 2012 in the 3rd Pediatrics Department in Cluj-Napoca. The inclusion criteria were: patients aged one month to 3 years, with acute respiratory diseases evolving into acute respiratory failure, $\mathrm{di}=$ agnosed on the basis of clinical parameters (dyspnea, tachypnea, nasal flaring, head bobbing, moaning, intercostal, subcostal and supraclavicular retraction recession), and paraclinical parameters (oxygen saturation measured in capil- 
408

lary blood by pulse oximeter $-\mathrm{SpO}_{2}$ and capillary blood gas parameters on $\mathrm{pH}$ Astrup - arterial or capillary blood gas $-\mathrm{SaO}_{2}$ ). Informed consent was obtained from family members. Patients with chronic respiratory failure, cardiac pathology and prematurity were excluded from the study. Each case was evaluated by determining a clinical score (Wood, 1975; Butnariu et al., 2005), which appraised five parameters (Tab. 1) according to intensity quantified as: absence (0), medium presence (1), and severe presence (2). $\mathrm{SpO} 2$ was monitored using a H100N (EDNA) pulse oximeter (noninvasive method), after a state of equilibrium had been reached, while $\mathrm{SaO}_{2}$ (blood gas parameters in arterialized capillary blood) was monitored using Blood Gas System AVL 995 - Medical Instruments Graz Austria. The blood had been collected after prior extremity massaging. These measurements were conducted before, and $30 \mathrm{~min}$ and $60 \mathrm{~min}$, respectively, after the initiation of oxygen therapy.

Tab. 1. Clinical appraisal score of respiratory failure

\begin{tabular}{|c|c|}
\hline Clinical parameter & Points \\
\hline $\begin{array}{c}\text { Respiratory rate } \\
\text { normal } \\
\text { bradypnea }(<\text { normal value }) \\
\text { tachypnea }(>\text { normal value })\end{array}$ & $\begin{array}{l}0 \\
1 \\
2\end{array}$ \\
\hline $\begin{array}{c}\text { Nasal flaring } \\
\text { absent } \\
\text { present } \\
\text { present + head bobbing / moaning }\end{array}$ & $\begin{array}{l}0 \\
1 \\
2\end{array}$ \\
\hline $\begin{array}{c}\text { Retraction } \\
\text { absent } \\
\text { intercostal or subcostal } \\
\text { intercostal and supraclavicular } \\
\text { and subcostal }\end{array}$ & $\begin{array}{l}0 \\
1 \\
2\end{array}$ \\
\hline $\begin{array}{l}\text { Cyanosis } \\
\text { absent } \\
\text { perioral while crying } \\
\text { perioral at rest }\end{array}$ & $\begin{array}{l}0 \\
1 \\
2\end{array}$ \\
\hline $\begin{array}{c}\text { Sensorial } \\
\text { normal } \\
\text { agitated child } \\
\text { drowsy / lethargic child }\end{array}$ & $\begin{array}{l}0 \\
1 \\
2\end{array}$ \\
\hline
\end{tabular}

Intensity: 0 = absence, 1 = medium presence, 2 = severe presence Adapted from: Wood (1975) and Butnariu et al. (2005)

Acute respiratory failure was classified according to the value of $\mathrm{SaO}_{2}$ into grade I: $\mathrm{SaO}_{2}=90-92 \%$, grade II: $\mathrm{SaO}_{2}=85 \%-89 \%$, and grade III: $\mathrm{SaO}_{2}=80 \%-84 \%$.

\section{Statistical analysis}

The qualitative variables were summarized as absolute frequencies, and relative frequencies and $95 \%$ confidence interval (95\% CI, values provided in squared brackets), respectively, calculated by applying a method similar to those presented in (Bolboacă and Jäntschi, 2008; Jäntschi and Bolboacă, 2010). The Z-test for proportions was ap- plied in order to identify statistically significant differences between two groups, by using a significance threshold of $5 \%$.The quantitative variables were summarized as means and standard deviations in the case of data that had normal distribution, and as median and variation interval for which the lower limit was the $25^{\text {th }}$ percentile and the higher limit the $75^{\text {th }}$ percentile in the case of quantitative data that did not follow normal distribution.

Comparisons of repeated measurements were performed by appropriate parametric (paired t-test, repeated measurements ANOVA with Bonferroni correction) or non-parametric tests (Mann-Whitney U test, Sing in ANOVA, Sign test), adjusting the significance threshold accordingly ( 0.05 for comparison of two groups and 0.0167 for comparison of three groups). The Statistica v. 8 program was used for statistical analysis. Some of the graphical representations were created in Microsoft Excel.

\section{Results}

A number of 74 patients suffering from acute respiratory failure caused by respiratory diseases were included in the study; oxygen therapy was delivered by simple face mask to 38 patients $(51.35 \%[39.21 ; 63.50])$, and by nasal cannula to 36 patients $(48.65 \%[36.51 ; 60.79])$.The characteristics of the subjects included in the study are given in Tab. 2.

Tab. 2. General characteristics of subjects with acute respiratory failure included in the study

\begin{tabular}{|c|c|c|c|}
\hline \multirow{2}{*}{ Characteristics } & \multicolumn{2}{|c|}{ Oxygen therapy } & \multirow{2}{*}{ p-value } \\
\hline & Simple face mask & Nasal cannula & \\
\hline Age (months) a & $15.66 \pm 11.11$ & $14.89 \pm 9.17$ & 0.7472 \\
\hline $\begin{array}{l}\text { Gender }^{\mathrm{b}} \\
\text { Female } \\
\text { Male }\end{array}$ & $\begin{array}{l}39.47[23.75 ; 57.83] \\
60.53[42.18 ; 76.25]\end{array}$ & $\begin{array}{l}36.11[19.52 ; 52.70] \\
63.89[47.30 ; 80.48]\end{array}$ & 0.7655 \\
\hline $\begin{array}{c}\text { Area of origin b } \\
\text { Rural } \\
\text { Urban }\end{array}$ & $\begin{array}{l}52.63[36.91 ; 68.35] \\
47.37[31.65 ; 63.09]\end{array}$ & $\begin{array}{l}50.00[33.41 ; 66.59] \\
50.00[33.41 ; 66.59]\end{array}$ & 0.8210 \\
\hline $\begin{array}{l}\text { Birth weight } \\
\text { (kg) a }\end{array}$ & $3.32 \pm 0.48$ & $3.18 \pm 0.49$ & 0.2298 \\
\hline $\begin{array}{c}\text { Current } \\
\text { weight }(\mathrm{kg}) \mathrm{a}\end{array}$ & $9.82 \pm 3.15$ & $9.85 \pm 3.03$ & 0.9636 \\
\hline Height $(\mathrm{cm})$ a & $77.32 \pm 12.51$ & $76.39 \pm 10.76$ & 0.7342 \\
\hline $\begin{array}{c}\text { Body mass } \\
\text { index a }(\mathrm{n} 1=16, \\
\mathrm{n} 2=18)\end{array}$ & $15.67 \pm 1.93$ & $16.47 \pm 1.78$ & 0.2223 \\
\hline $\begin{array}{l}\text { Ponderal index c } \\
(\mathrm{n} 1=21, \mathrm{n} 2=18)\end{array}$ & $1.08(1.01 ; 1.20)$ & $1.05(0.99 ; 1.10)$ & 0.2719 \\
\hline $\begin{array}{l}\text { Temperature } \\
\text { on admissionc }\end{array}$ & $37.4(36.8 ; 38.2)$ & $37.3(36.8 ; 38.4)$ & 0.8381 \\
\hline $\begin{array}{c}\text { Grade of ARF b } \\
\text { I } \\
\text { II } \\
\text { III }\end{array}$ & $\begin{array}{c}36.84[21.12 ; 55.19] \\
47.37[31.65 ; 63.09] \\
15.79[5.33 ; 31.51]\end{array}$ & $\begin{array}{c}36.11[19.52 ; 52.70] \\
55.56[38.97 ; 72.15] \\
8.33[2.86 ; 22.15]\end{array}$ & $\begin{array}{l}0.9480 \\
0.4796 \\
0.3197\end{array}$ \\
\hline
\end{tabular}

a mean \pm standard deviation; independent samples t-test; $\mathrm{b} \%[$ IC 95\%], where IC $95 \%=95 \%$ confidence interval; Z-test forcomparing two proportions; $\mathrm{c}$ median (Q1; Q3), where Q1 $=25^{\text {th }}$ percentile, Q3 $=7^{\text {th }}$ percentile; Mann-Whitney U test 
The age of the patients with grade I acute respiratory failure included in the study proved to be significantly younger $(9.04 \pm 8.29$ months, $\mathrm{n}=27)$ both compared to the age of patients with grade II acute respiratory failure $(17.66 \pm 9.48$ months, $n=38)$, and compared to the age of patients with grade III acute respiratory failure

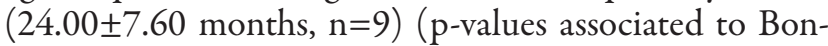
ferroni post-hoc test: $7.30 \cdot 10^{-4}$ for ARF I vs. ARF III; $1.17 \cdot 10^{-4}$ for ARF I vs. ARF III).

The clinical scores of the subjects included in the study, who were delivered oxygen therapy by simple face mask and nasal cannula, respectively, measured on inclusion in the study and 30 minutes and 60 minutes, respectively, after the initiation of oxygen therapy are given in Fig. 1 and Fig. 2, respectively.

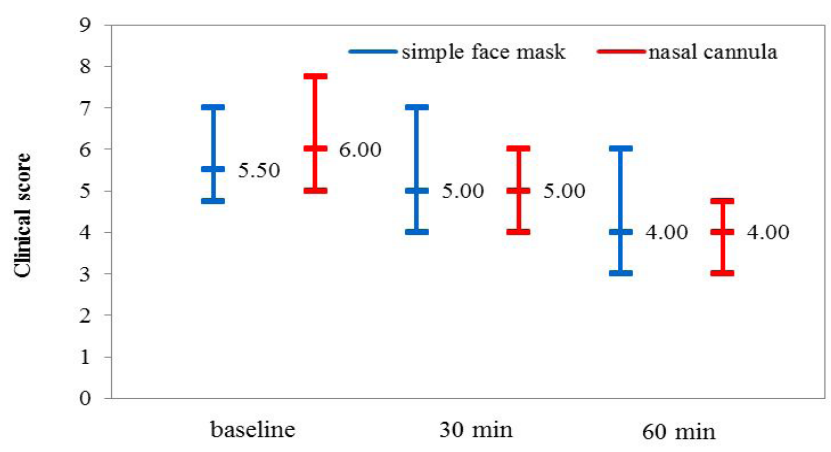

Fig. 1. The clinical score in moment 0 (baseline), and $30 \mathrm{~min}$ utes and 60 minutes after oxygen therapy by simple face mask (blue) and by nasal cannula (red). The middle points represent the value of median while the extreme points are the $25^{\text {th }}$ and $75^{\text {th }}$ percentiles

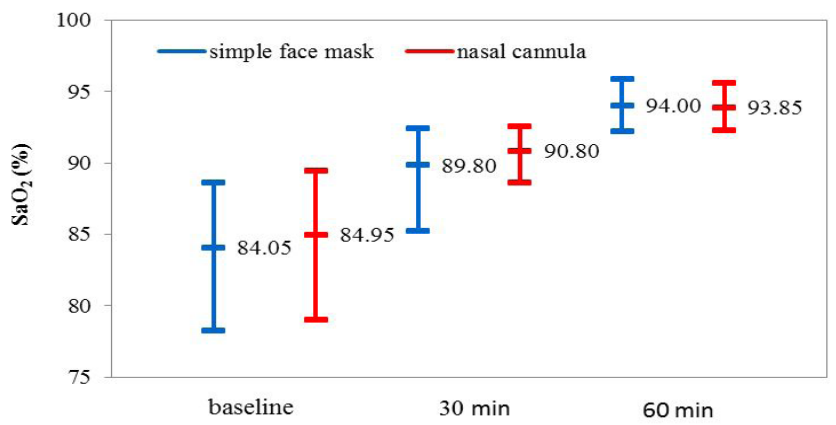

Fig. 2. $\mathrm{SaO}_{2}$ in moment 0 (baseline), and 30 minutes and $60 \mathrm{~min}$ utes after oxygen therapy by simple face mask (blue) and by nasal cannula (red). The middle points represent the value of median while the extreme points are the $25^{\text {th }}$ and $75^{\text {th }}$ percentiles

Statistically significant differences were identified between the clinical scores calculated dynamically after oxygen therapy by simple face mask: Friedman ANOVA: statistics $=65.09, \mathrm{p}<0.001$ ( $\mathrm{p}$-value associated to Sign test: $1.77 \cdot 10^{-4}$ for baseline vs. 30 minutes; $1.95 \cdot 10^{-9}$ for baseline vs. 60 minutes; $4.25 \cdot 10^{-8}$ for 30 minutes vs. 60 minutes); nasal cannula: Friedman ANOVA: statistics $=64.58, \mathrm{p}<$
0.001 (p-value associated to Sign test: 0.0077 for statistics; $5.43 \cdot 10^{-9}$ for baseline vs. 60 minutes; $2.54 \cdot 10^{-8}$ for $30 \mathrm{~min}$ utes vs. 60 minutes).

No significant differences were identified between the values of the clinical score calculated on baseline, and after 30 minutes and 60 minutes, respectively, between the two studied groups (baseline: $\mathrm{Z}$ (Mann-Whithey $\mathrm{U}$ test) = $-0.2758, p=0.7827 ; 30$ minutes: $Z=0.5678, p=0.5702$; $\mathrm{Z}=0.3082, \mathrm{p}=0.7579)$. The distribution of $\mathrm{SaO}_{2}$ and $\mathrm{SpO}_{2}$ according with the type of oxygen therapy is presented in Figs. 2 and 3.

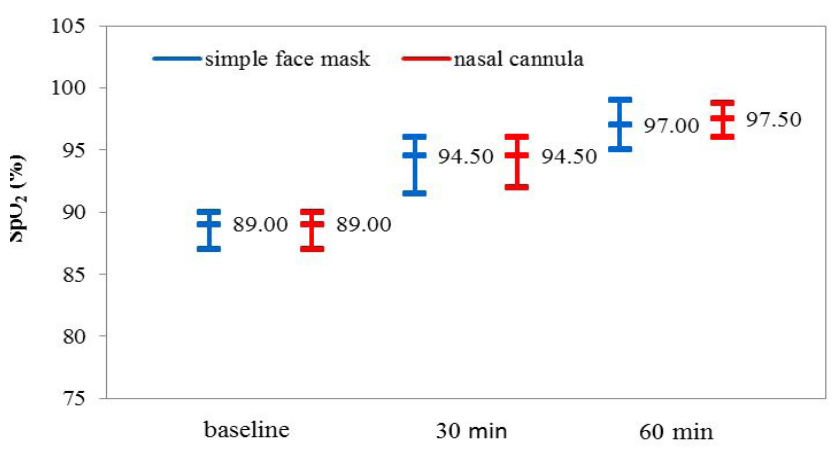

Fig. 3. $\mathrm{SpO}_{2}$ in moment 0 (baseline), and 30 minutes and 60 minutes after oxygen therapy by simple face mask (blue) and by nasal cannula (red). The middle points represent the value of median while the extreme points are the $25^{\text {th }}$ and $75^{\text {th }}$ percentiles

The comparison of $\mathrm{SaO}_{2}$ and $\mathrm{SpO}_{2}$ in the subjects who were delivered oxygen therapy by simple face mask and nasal cannula is given in Tab. 3 .

Tab. 3. Comparison of $\mathrm{SaO}_{2}$ and $\mathrm{SpO}_{2}$ in the subjects who were delivered oxygen therapy by simple face mask and nasal cannula

$\mathrm{p}$-value associated to Sign test

\begin{tabular}{cccccc|}
\hline Group & Variable & $\begin{array}{c}\text { Friedman ANOVA } \\
(\mathrm{p} \text {-value })\end{array}$ & $\begin{array}{c}\text { Baseline vs. } \\
30 \text { minutes }\end{array}$ & $\begin{array}{c}\text { Baseline vs. } \\
60 \text { minutes }\end{array}$ & $\begin{array}{c}30 \text { minutes vs. } \\
60 \text { minutes }\end{array}$ \\
\hline $\begin{array}{c}\text { Simple } \\
\text { face mask }\end{array}$ & $\mathrm{SaO}_{2}(\%)$ & $66.36(<0.001)$ & $1.36 \cdot 10^{-8}$ & $1.36 \cdot 10^{-8}$ & $8.64 \cdot 10^{-8}$ \\
& $\mathrm{SpO}_{2}(\%)$ & $74.05(<0.001)$ & $1.95 \cdot 10^{-9}$ & $1.95 \cdot 10^{-9}$ & $1.36 \cdot 10^{-8}$ \\
\hline $\begin{array}{c}\text { Nasal } \\
\text { cannula }\end{array}$ & $\mathrm{SaO}_{2}(\%)$ & $64.39(<0.001)$ & $5.43 \cdot 10^{-9}$ & $5.43 \cdot 10^{-9}$ & $5.43 \cdot 10^{-9}$ \\
& $\mathrm{SpO}_{2}(\%)$ & $72.00(<0.001)$ & $3.80 \cdot 10^{-8}$ & $5.43 \cdot 10^{-9}$ & $1.34 \cdot 10^{-6}$ \\
\hline
\end{tabular}

\section{Discussion}

The two investigated groups of patients suffering from acute respiratory failure caused by respiratory diseases were homogenous in terms of age, weight, ponderal index, body mass index, and severity of respiratory failure grade of acute respiratory failure. 
410

The clinical studies that used clinical scores to evaluate patients with acute respiratory failure caused by respiratory diseases have demonstrated that the clinical score is extremely important both for the evaluation of the severity of acute respiratory failure, and for monitoring the patients evolution and response to treatment (Wood, 1972; Butnariu et al., 2005). We found that the values of the clinical score in the group who were administered oxygen therapy by simple face mask improved after 30 minutes and 60 minutes, respectively; the differences between the two measurements were statistically significant. The most obvious difference in $\mathrm{SaO}_{2}$ was recorded after 60 minutes vs. after 30 minutes from the initiation of oxygen therapy. We also found that the values of the clinical score in the group who were administered oxygen therapy by nasal cannula improved, and the differences were statistically significant, both after 30 minutes and after 60 minutes from the initiation of oxygen therapy. Several researchers have reported better tolerance in patients suffering from acute respiratory failure who were delivered oxygen therapy by nasal cannula than in those who were delivered oxygen therapy by simple face mask, due to the possibility of simultaneous oral feeding and oxygen therapy (Neal, 2010; Oriol et al., 2010).

Some studies have demonstrated that pulse oximetry $\left(\mathrm{SpO}_{2}\right)$, which is the noninvasive method, may be used to monitor patients with acute respiratory failure, in order to replace the $\mathrm{SaO}_{2}$ method, which is invasive (Modi et al., 2013; Foo et al., 2013). This study has demonstrated that the $\mathrm{SpO}_{2}$ values showed statistically significant increases both after 30 minutes and after 60 minutes from the initiation of oxygen therapy, by the two methods: simple face mask and nasal cannula (Tab. 3). The $\mathrm{SaO}_{2}$ values recorded statistically significant increases both after 30 minutes and after 60 minutes from the initiation of oxygen therapy, both by simple face mask and nasal cannula. The specialized literature specifies the importance of initial evaluation and periodical reevaluation of $\mathrm{SaO}_{2}$ in patients with acute respiratory failure caused by respiratory diseases by both $\mathrm{SaO}_{2}$ and $\mathrm{SpO}_{2}$ (Duke et al., 2009; Catto et al., 2011).

The analysis of Fig. 2 and 3 revealed that the values of $\mathrm{SpO}_{2}$ were systematically higher compared to values of $\mathrm{SaO}_{2}$ in both oxygen therapy methods (simple face mask and nasal cannula). Despite this, similar values of $\mathrm{SaO}_{2}$ and $\mathrm{SpO}_{2}$ were obtained respective of the used oxygen therapy suggesting the absence of significant differences between these methods. The difference between $\mathrm{SpO}_{2}$ and $\mathrm{SaO}_{2}$ in regards of median values seems to be similar in time and varied from 5 to $6 \%$ for simple face mask and from 3.5 to $5 \%$ for nasal cannula. This result suggests that the $\mathrm{SaO}_{2}$ could be measured at the baseline and the evaluation could be done using $\mathrm{SpO}_{2}$.

The efficiency of oxygen therapy by simple face mask and by nasal cannula for acute respiratory failure infants and young children was conducted as a cohort study and thus it is not possible to generalize the obtained results.
Other limits of our study are represented by the small number of subjects included in the study and the absence of oxygen therapy randomization. Larger multicenter studies are needed to validate the results reported in this study.

\section{Conclusions}

Determining the clinical score for acute respiratory failure is useful for the appraisal of the patients' outcome and response to oxygen therapy. The clinical score for acute respiratory failure and the value of $\mathrm{SaO}_{2}$ and $\mathrm{SpO}_{2}$ showed statistically significant improvement after oxygen therapy. No statistically significant differences were found between $\mathrm{SaO}_{2}$ after oxygen therapy by simple face mask and nasal cannula after 30 minutes and 60 minutes from the initiation of oxygen therapy. If other future randomized studies will have the same results, the $\mathrm{SpO}_{2}$ may be used to monitor non-invasively instead the $\mathrm{SaO}_{2}$.

\section{References}

AARC (2002). Clinical Practice Guideline, Selection of an Oxygen Delivery Device for Neonatal and Pediatric Patients - 2002 Revision @ Update. Resp Care 47:707-716.

Acalovschi I (2002). Anesthesia and intensive care. 2nd Edition, Clusium, p. 75-78.

Andreica M, Miu N (2010). Pediatrics, p. 107-114. University Medical Publishing House "Iulius Hatieganu”, Cluj-Napoca, Romania.

Bolboacă SD, Jäntschi L (2008). Optimized Confidence Intervals for Binomial Distributed Samples. Int J Pure Appl Math 47(1):1-8

Butnariu A., Chindris AM, Giurgiu D, Leucuta A (2005). Correlation between Fever and the Clinical Severity of Acute Bronchiolitis. Pneumologia 54(3):154-157.

Catto AG, Zgaga L, Theodoratou E, Huda T, Nair H, El Arifeen S, Rudan I, Duke T, Campbell H (2011). An evaluation of oxygen systems for treatment of childhood pneumonia. BMC Public Health 11(Suppl 3):S28.

Duke T, Subhi R, Peel D, Frey B (2009). Pulse oximetry: technology to reduce child mortality in developing countries. Ann Trop Paediatr 29(3):165-175.

Foo JY, Chua KP, Tan XJ (2013). Clinical applications and issues of oxygen saturation level measurements obtained from peripheral sites. J Med Eng Technol 37(6):388-395.

Frankel LR, DiCarlo V (2003). Acute (Adult) Respiratory Distress Syndrome, p. 316-317. In: Behrman RE, Kliegman RM, Jenson HB (Eds.). Nelson Textbook of Pediatrics. 17th Edition, Elsevier.

Gherasim L (2003). Respiratory Diseases. Rheumatic Diseases, p. 563-597. In: Internal Medicine. 2nd Edition. Medical Publishing House, Bucharest.

Ionescu D (2010). Notions of Anesthesia and Intensive Care, House of Books of Science, p. 236-241. 
Jäntschi L, Bolboacă SD (2010). Exact Probabilities and Confidence Limits for Binomial Samples: Applied to the Difference between Two Proportions. TheScientificWorld Journal 10:865-878.

Lee JH, Rehder KJ, Williford L, Cheifetz IM, Turner DA (2013). Use of high flow nasal cannula in critically ill infants, children, and adults: a critical review of the literature. Intensive Care Med 39(2):247-257.

Man SC, Nanulescu MV (2006). Pediatric Practice, p. 61-103. In: Publisher Risoprint, Cluj-Napoca, Romania.

Modi P, Munyaneza RBM, Goldberg E, Choy G, Shailam R, Sagar P, Westra SJ, Nyakubyara S, Gakwerere M, Wolfman V, Vinograd A, Moore M, Levine AC (2013). Oxygen Saturation Can Predict Pediatric Pneumonia in a Resource-Limited Setting. J Emerg Med 45(5):752-760jemermed.2013.04.041.
Neal J (2010) Defining acute lung disease in children with the oxygenation saturation index. Pediatr Crit Care Med 11(1):12-17.

Roca O, Riera J, Torres F, Masclans JR (2010). High-Flow Oxygen Therapy in Acute Respiratory Failure. Respir Care 55(4):408-413.

Wood DW (1972). Clinical scoring system for children with status asthmaticus. Am J Dis Child 123:227-231.

Stoll BJ, Kliegman RM (2003). Respiratory Tract Disorders, p. 574-575. In: Nelson Textbook of Pediatrics 17th edition: In: Behrman RE, Kliegman RM, Jenson HB (Eds.). Nelson Textbook of Pediatrics. $17^{\text {th }}$ Edition, Elsevier. 